\title{
非定常運動翼後流の渦流れと非定常推進力*
}

\author{
㴊 脇 正 樹*1, 田 中 和 博*1, 永 山勝 也*1
}

\section{Vortex Flow and Dynamic Thrust of an Unsteady Airfoil}

\author{
Masaki FUCHIWAKI*2, Kazuhiro TANAKA and Katsuya NAGAYAMA \\ ${ }^{* 2}$ Department of Mechanical Information Science and Technology, Kyushu Institute of Technology, \\ 680-4 Kawazu, Iizuka-shi, Fukuoka, 820-8502 Japan
}

\begin{abstract}
In order to clarify the vortex flow behind a pitching/heaving airfoil and the characteristics of dynamic thrust acting on them at low Reynolds number region, we have carried out PIV measurement behind both airfoils and have measured the dynamic thrust acting on them. Increasing the nondimensional velocity in pitching/heaving motion, the thrust producing vortex street is clearly formed behind both airfoils. The averaged dynamic thrust acting on them increased as the nondimensional velocity increased. The hysteresis loops of dynamic thrust acting on a pitching/heaving airfoil had concavity/convexity shape characteristics, respectively. The behaviors of the dynamic thrusts strongly depend on the non-dimensional trailing edge velocity and the non-dimensional heaving velocity. The thrust efficiency of a pitching airfoil increased up to $V_{p}=0.7$ and the maximum thrust efficiency was 0.34 . On the other hand, the thrust efficiency of a heaving airfoil increased up to $V_{h}=0.4$ and the maximum thrust efficiency was 0.20 .
\end{abstract}

Key Words: Unsteady Flow, Vortex, Wake, Flow Visualization, Fluid Force, Thrust, Pitching Airfoil, Heaving Airfoil

\section{1. 緒 論}

近年, MEMS (Micro-Electro-Mechanical-Systems）技術の急速な発達や，水生動物および昆虫の遊 泳・飛翔メカ二ズムが多くの関心を集めていることな ぞにより, 低レイノルズ数領域の流れ場が注目されつ つある。そのため, 低レイノルズ数領域における非定 常流れに関する研究が多数行われ，特に非定常運動翼 まわりの流れ場に関する研究が実験および数值解析に より報告されている(1)(2). Fuchiwaki ら ${ }^{(3)}$ は, 低レイ ノルズ数領域 $\left(R e=4.0 \times 10^{3}\right)$ におけるピッチング運 動翼から発生する離散的はく離渦をシュリーレン可視 化法によりとらえ，その発生周波数について明らかに した.さらには, $R e=4.0 \times 10^{4}$ において各種翼形状 のピッチング運動翼に働く非定常流体力特性を実験的 に明らかにしている(4). Shih ら ${ }^{(5)}$ は, $R e=5.0 \times 10^{3}$ におけるピッチング運動翼まわりの非定常はく離を PIDV (Paticle-Image-Displacement-Velocimetry) 計測によりとらえている. Rank ら ${ }^{(6)}$ は, Re $=1.52 \times$

\footnotetext{
* 原稿受付 2006 年 11 月 6 日

*1 正員, 九州工業大学情報工学部( $\$$ 820-8502 飯塚市川津 680-4).

E-mail : futiwaki@mes.kyutech.ac.jp
}

$10^{5}$ におけるピッチング運動翼まわりの非定常はく離 をPIV 計測によりとらえている.

また, 非定常運動翼後流の流れ場についての研究も 多く報告されている. Peter $^{(7)}$ は $R e=0.012-1.20 \times$ $10^{4}$ におけるピッチング運動翼後流に推進渦列構造が 形成されることを報告している．Koochesfahani ら は, $R e=1.2 \times 10^{4}$ におけるピッチング運動翼後流を 可視化し, その二次元および三次元構造を明らかにし ている. Fuchiwaki ら ${ }^{(9)}$ は, $R e=4.0 \times 10^{3}$ における ピッチング運動翼後流を可視化し, 無次元角速度, ピ ッチング振幅, 運動波形による推進力発生渦列構造に ついて明らかにした.また, Jonesら ${ }^{(10)}$ は, $R e=$ $0.05-5.0 \times 10^{4}$ におけるヒービング運動翼後流に Knoller-Betz effect と呼ばれる渦構造の形成と推進 力の発生を実験的, 数值解析的に報告している. Joseph ${ }^{(11)}$ は, ヒービング運動翼をバックステップ流れ や鈍頭物体後流に設置し，発生するはく離流れが制御 可能であることを報告している. Lai ら ${ }^{(12)}$ は $R e=$ $0.05-2.1 \times 10^{4}$ におけるヒービング運動翼後流の可 視化実験，また，パネル法を用いた数值解析により後 流のフローパターンを明らかにし，さらには，LDV 計 測による後流速度分布測定からヒービング運動翼に働 く推進力特性を報告している. Jones ら ${ }^{(13)}$ は，ヒービ 
ング運動翼の推進機構を利用した MAV (Micro-AirVehicle)の開発を行っている. Yang ら ${ }^{(14)}$ はヒービ ング運動翼に働く非定常流体力特性を報告している. さらには, Ramamurti ら ${ }^{(15)}$ は, 有限要素解析ツール により $R e=1.2 \times 10^{4}$ におけるピッチング運動および ピッチング運動とヒービング運動が組合った非定常運 動翼に働く非定常推進力特性について報告している. しかしながら, 非定常運動翼後流とそれに働く非定常 推進力の関連性についての報告は十分になされていな い. そこで, 本研究では, 代表的な非定常運動である ピッチング運動およびヒービング運動を行う翼を対象 とし, 低レイノルズ数領域における非定常運動翼後流 の渦流れとそれに働く非定常推進力特性を実験的に明 らかにすることを目的としている. 対象称 NACA 0010 を対象に, $R e=4.0 \times 10^{3}$ においてピッチング運 動翼およびヒービング運動翼後流の PIV 計測を行い, 後流のフローパターン, その渦度および渦度に誘起さ れる後流の増速部を明らかにする.また，これらに働 く非定常推進力を小形六軸力覚センサにより測定し, ピッチング運動翼およびヒービング運動翼に働く非定 常推進力特性について明らかにする。

\section{2. おもな記 号}

$$
\begin{aligned}
& A: \text { ピッチング振幅角 } \\
& a: \text { ヒービング振幅 } \\
& a^{\prime}: \text { ピッチング運動における翼後縁振幅 } \\
& c: \text { 翼弦長 } \\
& C_{L}: \text { 揚力係数 } \quad=L /(1 / 2) \rho V_{0}^{2} c l \\
& C_{M}: \text { モーメント係数 } \quad=M /(1 / 2) \rho V_{0}^{2} c l^{2} \\
& \left.C_{T} \text { : 推進力係数 } \quad=T_{h} /(1 / 2) \rho V_{0}^{2} c l \text { (ヒービング }\right) \\
& \left.\quad=T_{p} /(1 / 2) \rho V_{0}^{2} c l \text { (ピッチング }\right)
\end{aligned}
$$

$f_{h}:$ ヒービング周波数

$f_{p}:$ ピッチング周波数

$h:$ 無次元ヒービング振幅 $=a / c$

$h^{\prime}$ : 無次元ピッチング翼後縁振幅 $=a^{\prime} / c$

$l:$ 翼スパン長さ

$L:$ ヒービング運動翼に働く揚力

$M:$ ピッチング運動翼に働くモーメント

$R e$ : 翼弦基準レイノルズ数 $=c V_{0} / \nu$

$T$ ：周期

$T_{h}:$ ヒービング運動翼に働く推進力

$T_{p}:$ ピッチング運動翼に働く推進力

$v:$ 翼後流の流速

$V:$ ヒービング速度

$V_{h}:$ 無次元ヒービング速度 $=2 \pi f_{h} a / V_{0}$

$V_{0}:$ 主流速度
$V_{p}:$ ピッチング運動における翼後縁無次元速度 $=2 \pi f_{h} a^{\prime} / V_{0}$

$V^{\prime}:$ 無次元流速 $=v / V_{0}$

$x: x$ 方向の翼の位置

$y: y$ 方向の翼の位置

$\alpha_{m}$ : 基本迎え角

$\rho:$ 密度

$\nu$ : 動粘性係数

$\omega:$ ピッチング運動翼の角速度

$\eta$ : 推進効率

添字

$h:$ ヒービング運動

p:ピッチング運動

\section{3. 実 験 方 法}

$3 \cdot 1$ 実験装置 実験装置は図 1 に示すように回 流水槽, 供試翼, 加振装置, 水冷アルゴンイオンレー ザ，平面鏡，高速度カメラおよび PIV 計測装置により 構成されている。供試翼は対称翼 NACA 0010 であ り,その翼弦長および翼スパン長さはそれぞれ $c=$ $0.06 \mathrm{~m}, l=0.20 \mathrm{~m}$ である. PIV 計測用のトレーサ粒 子は, ORGASEL(Kanomax 社)を用い, その直径は 約 $50 \mu \mathrm{m}$ である.ヒービング運動は, DCサーボモー タの回転運動をボールねじにより並進運動へと変換す ることにより実現されている，また，ピッチング運動 翼の加振装置 ${ }^{(4)}$ は DC サーボモータの回転運動を供試 翼へ直接伝えている. 回流水槽底部と供試翼のすきま は約 $1 \mathrm{~mm}$ とし，また一方で回流水槽上部に平板を設 置することにより翼端の三次元性を抑えている.

$3 \cdot 2$ 非定常推進力測定装置 非定常推進力は, 小形六軸力覚センサにより測定されている(4). 供試翼 はつり下げ式に設置されており，ピッチング運動およ びヒービング運動の軸の摇れを抑えるために翼下端は

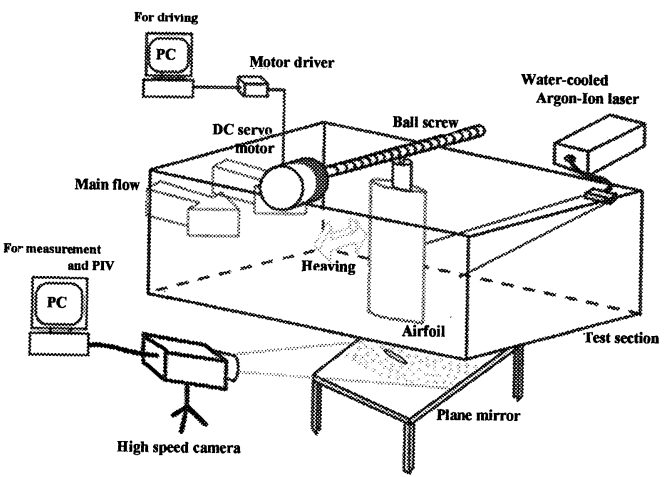

Fig. 1 Experimental apparatus for PIV measurement 


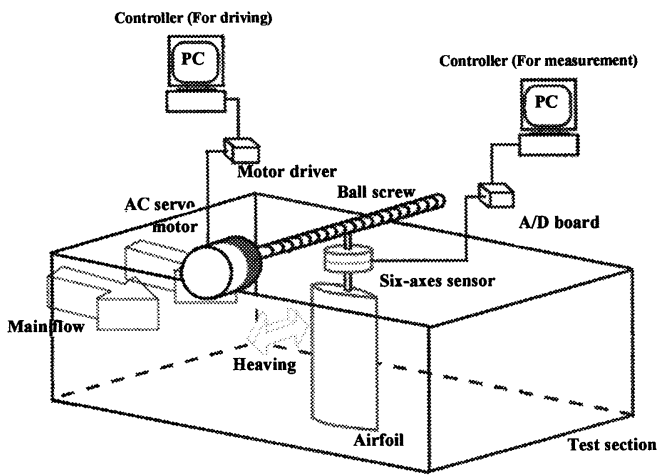

Fig. 2 Experimental apparatus for dynamic thrust measurement

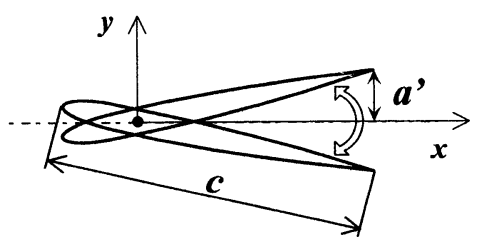

(a) Pitching airfoil

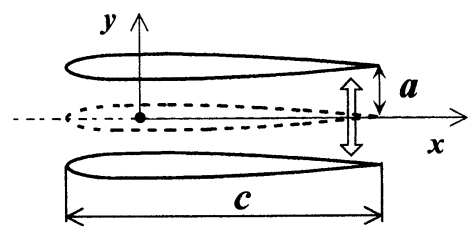

(b) Heaving airfoil

Fig. 3 Airfoil configuration and unsteady motions

回流水槽底部からも一点支持されている. 小形六軸力 覚センサは $x, y, z$ 方向の力およびモーメントが測定 可能であり，本実験では，小形六軸力覚センサにより 得られた負の抗力を推進力としている. 小形六軸力覚 センサにより得られたデー夕はFFT 解析処理により 慣性量を差引いた後に, 逆 FFT 解析処理により時系 列データに戻している.

$3 \cdot 3$ 実験条件 流れの可視化実験における翼弦 基準レイノルズ数は $R e=4.0 \times 10^{3}$ とする. 翼弦基準 レイノルズ数 $R e=4.0 \times 10^{4}$ においては, PIV 計測実 験により明瞭な可視化実験結果が得られなかった。一 方, 非定常運動翼に働く非定常流体力特性は $R e=4.0$ $\times 10^{3}$ と $4.0 \times 10^{4}$ の間に大きな違いが表れなかったの で, 非定常流体力特性については $R e=4.0 \times 10^{4}$ のデ ー夕を利用するが，そのときのフローパターンは Re $=4.0 \times 10^{3}$ のフローパターンと同一視しても問題な
いと考える.

供試翼のピッチング運動およびヒービング運動は図 3 に示すような回転運動および並進運動であり, とも に正弦波振動で与える.いずれの運動の場合も基本迎 え角 $\alpha_{m}=0^{\circ}$ である. 本実験では, $V_{p}=0.2 \sim 2.2, h^{\prime}$ $=0.078,0.117,0.156,0.194$ お よび $V_{h}=0.1 \sim 1.69$, $h=0.15,0.23,0.30,0.38$ を用いた。また, ピッチン グ運動の回転中心は翼前縁より $1 / 4$ 弦長, ピッチング 振幅 $A=6,9,12^{\circ}$ および $15 \mathrm{deg}$. である.

\section{4. 結果および考察}

$4 \cdot 1$ 非定常運動翼の後流構造 PIV 計測実験に よるピッチング運動翼およびヒービング運動翼後流の 等渦度線図をそれぞれ図 4 および図 5 に示す. 図 4(a)，（b）はそれぞれ $h^{\prime}=0.156$ における $V_{p}=0.90$, 1.35 の結果を示し, 図5(a), (b)はそれぞれ $h=$ 0.30 における $V_{h}=0.90,1.35$ の結果を示す. 渦度の 値の正および負は, それぞれ渦の反時計方向回転およ び時計回転方向を意味している.

ピッチング運動翼の $V_{p}=0.90$, では, 翼背面から 巻き上がる渦 (負) と翼腹面より巻き上がる渦 (正)の位 置がカルマン渦列とは逆転し, 推進力発生渦列(逆力 ルマン渦列)を形成していることがわかる[図 $4(\mathrm{a})] . V_{p}=1.35$ に増加すると, 渦間隔が密になる だけでなく, 渦度も大きくなっていることもわかる. また, 推進力発生渦列はより明瞭に形成され, さらに は，その渦列は主流に対して対称とならずに傾いてい る(9) $[$ 図 4(b)].これは，翼背面および腹面から巻き 上がる渦の回転が強くなるために, 両者のバランスが 崩れることにより発生する. Lai ら ${ }^{(12)}$ が行ったプラ ンジング運動翼後流にも高無次元プランジング速度の 場合に形成されている.

ヒービング運動翼の場合も $V_{h}=0.90$ において, 翼 後流には推進力発生渦列が形成されていることがわか る [図 $5(\mathrm{a})] . V_{h}=1.35$ では, ピッチング運動翼と 同様に推進力発生渦列を形成する渦の間隔が密にな り，さらには渦度が高くなっている [図 $5(b)]$. ピッ チング運動翼に比べると明瞭ではないが, 推進力発生 渦列が主流に対し傾いて形成されている。 また，ヒー ビング運動翼後流に形成される推進力発生渦列を形成 する渦の渦度はピッチング運動翼の場合に比べて大き い.すなわち, ヒービング運動翼後流には, ピッチン グ運動翼に比べ, 同程度かそれ以上の強い回転をもつ 渦が巻き上がっている.

$4 \cdot 2$ 非定常運動翼後流の増速流 ピッチング運 動翼 $\left(h^{\prime}=0.156\right)$ およびヒービング運動翼 $(h=0.30)$ 


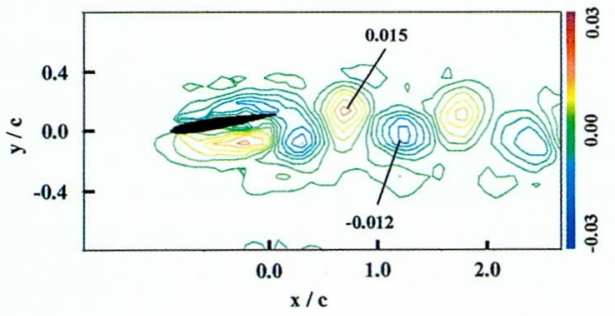

(a) $V_{p}=0.90$

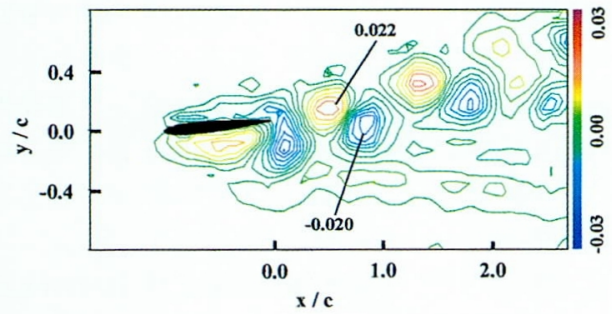

(b) $\quad V_{p}=1.35$

Fig. 4 Vorticity contours behind a pitching airfoil at $h^{\prime}$ $= \pm 0.156$

について, 一弦長後方の 1 周期分の平均速度分布をそ れぞれ図 6(a)，（b）に示す。横軸および縦軸にそれ ぞれ無次元流速 $V^{\prime}\left(=v / V_{0}\right)$ 抢よび翼の位置 $y / c$ を示 す. $V^{\prime}>1.0$ が増速部(ジェット)を意味している.

ピッチング運動翼の $V_{p}$ が増加するにつれピッチン グ運動翼後流の増速部が大きくなるだけでなく速度欠 損も大きくなっている [図 6(a)].また, $V_{p}=0.90$, 1.13 では, 増速部の速度分布は $y / c=0.0$ を中心に対 称に現れているが, $V_{p}=1.35$ では, 増速部は $y / c=$ 0.0 を中心非対称に現れる.等渦度線図の結果 [図 4(b ) ）より, 翼後流に形成される推進力発生渦列が 主流に対して傾いて形成されるために増速部も傾いて いる.

ヒービング運動翼の場合， $V_{h}$ の増加に伴い速度欠 損の大きさは変わらないものの増速部は大きくなって いる [図 6(b)]。また, ヒービング運動翼後流の増速 部はピッチング運動翼に比べて大きい.これは, 図 4 および図 5 に示すように, ヒービング運動翼の後流渦 列中の渦の渦度はピッチング運動翼の後流渦列中の渦 の渦度に比べ大きいためである。また，ヒービング運 動翼の場合には， $V_{h}=1.35$ においてもピッチング運 動翼に比べ推進力発生渦列の傾きは大きくない［図 5(b) ] ために増速部の非対称性も大きくない. しか しながら， $V_{h}=1.69$ ではピッチング運動翼の場合と 同様に推進力発生渦列が $y / c=0.0$ を中心に非対称に なることが確認されている.

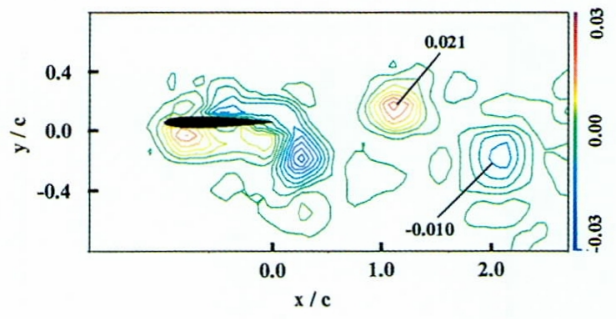

(a) $V_{h}=0.90$

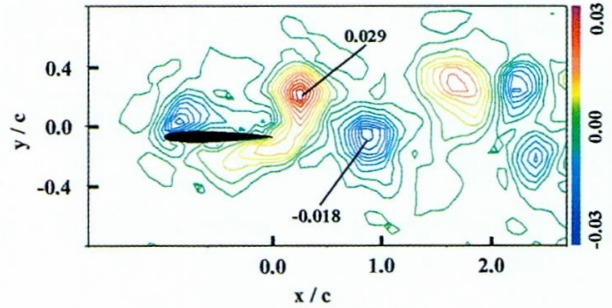

(b) $\quad V_{h}=1.35$

Fig. 5 Vorticity contours behind a heaving airfoil at $h$ $= \pm 0.30$

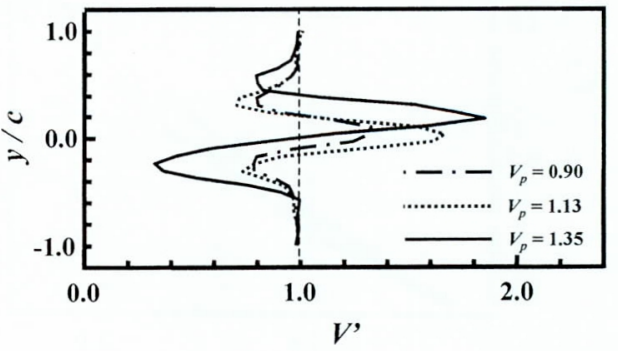

(a) Pitching airfoil

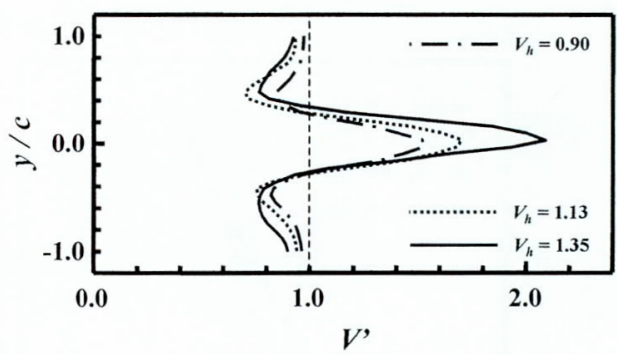

(b) Heaving airfoil

Fig. 6 Mean velocity profiles during one cycle behind one chord length distant from the trailing edge

ピッチング運動翼およびヒービング運動翼につい て, 一弦長後方の最大無次元流速 $V_{\max }^{\prime}$ を図 7 に示す. 横軸は $V_{p}$ と $V_{h}$ である。

図 7 より，ピッチング運動翼およびヒービング運動 


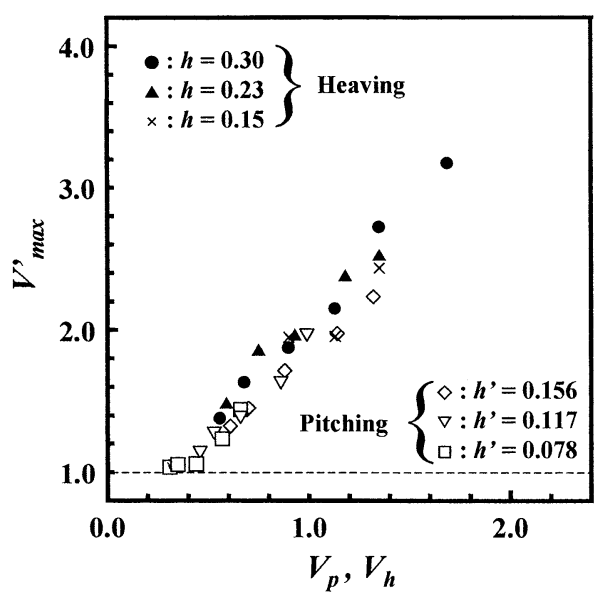

Fig. 7 Maximum jet velocity behind pitching and heaving airfoils

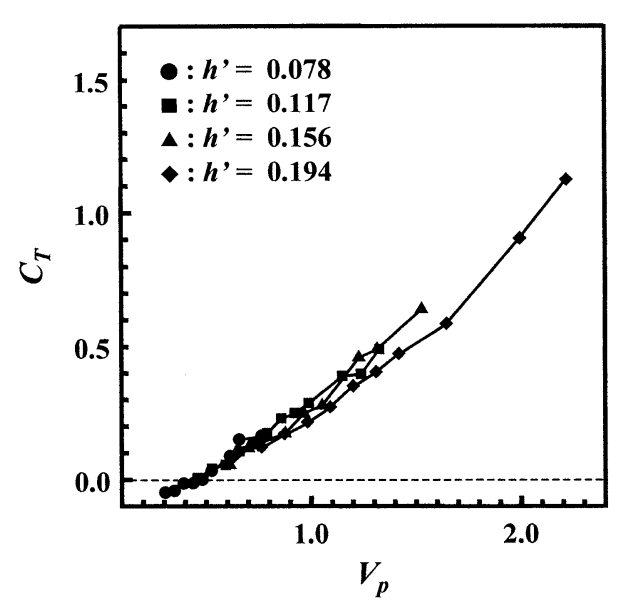

(a) Pitching airfoil

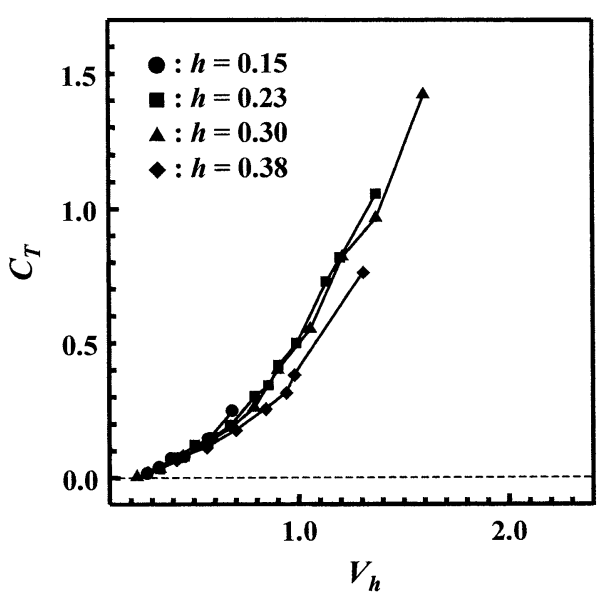

(b) Heaving airfoil

Fig. 8 Dynamic thrust averaged during one cycle
翼の $V_{p}$ および $V_{h}$ が増加するにつれ， $V_{\max }^{\prime}$ も増加し ていることと, ピッチング運動およびヒービング運動

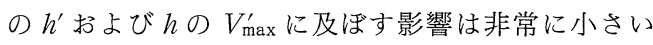
ことがわかる.

$4 \cdot 3$ 非定常運動翼に働く非定常推進力 ピッチ ング運動翼およびヒービング運動翼に働く非定常推進 力 $C_{T}$ の 1 周期あたりの平均値をそれぞれ図 $8(\mathrm{a})$, (b)に示す.

図 8(a)に示されるピッチング運動翼においては, $V_{p}$ が増加するにつれ, 非定常推進力の平均值は増加 している.また, 非定常推進力は $h^{\prime} に は$ 依存しない こともわかる. 図 8(b) に示されるヒービング運動翼 の場合も同様に, $V_{h}$ が増加するにつれ, 非定常推進 力の平均值は増加している. 非定常推進力の平均值は $h$ に依存しないことがわかる.

$V_{p}=0.97$ のピッチング運動翼および $V_{h}=0.91$ の ヒービング運動翼に働く非定常推進力のヒステリシス ループをそれぞれ図 9(a)，（b）に示す.図 9(a)の 実線捛よび破線はそれぞれ $h^{\prime}=0.117$ および 0.156 の 結果を示し, 図 9(b)の実線および破線はそれぞれ $h$ $=0.23$ および 0.30 の結果を示す. 図 9 中の矢印は七 ステリシスループの向きを表している.いずれのヒス テリシスループもピッチング運動およびヒービング運 動 20 周期分を 1 周期分に平均化している.

いずれの運動翼においても, 非定常推進力のヒステ

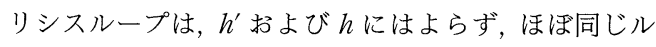
一プを描いている。この結果からも, 非定常推進力は $h^{\prime}$ おび $h$ の影響は非常に小さく, $V_{p}$ および $V_{h}$ に 強く依存することがわかる. また, 非定常推進力の七

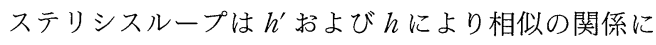
あり, 非定常推進力のヒステリシスループの大きさを 変えていることがわかる.

次に図10(a)，(b)に，融よびhがそれぞれ 0.156 および 0.30 のときのピッチング運動翼および ヒービング運動翼に働く非定常推進力のヒステリシス ループを示す.図10(a)の破線および実線はそれぞ れ $V_{p}=0.90$ および 1.35 の結果を示し, 図 $10(\mathrm{~b})$ の 破線および実線はそれぞれ $V_{h}=0.90$ および 1.35 の 結果を示す。図 10 中の矢印はヒステリシスループの 向きを表しており，また，○および○はそれぞれピッ チング運動およびヒービング運動の上死点および下死 点を示している.

ピッチング運動翼に働く非定常推進力のヒステリシ スループはいずれの $V_{p}$ においても凹形のヒステリシ スループを描き, 上死点 $\left(h^{\prime}=0.156\right)$ および下死点 $\left(h^{\prime}\right.$ $=-0.156)$ において最大の非定常推進力を発生して 


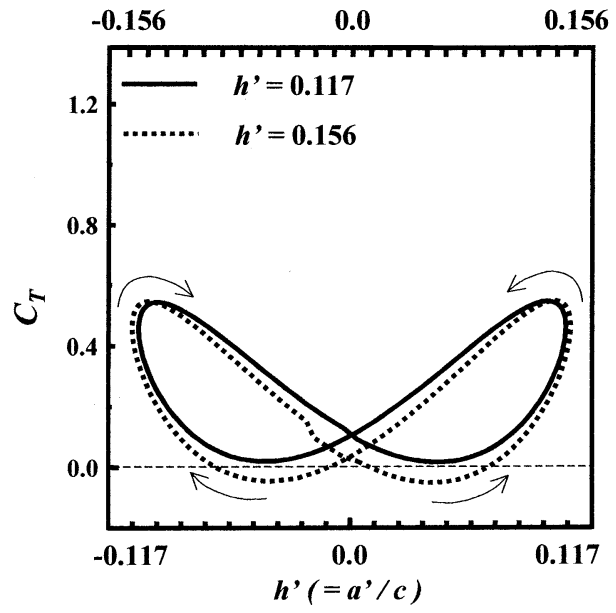

(a) Pitching airfoil at $V_{p}=0.97$

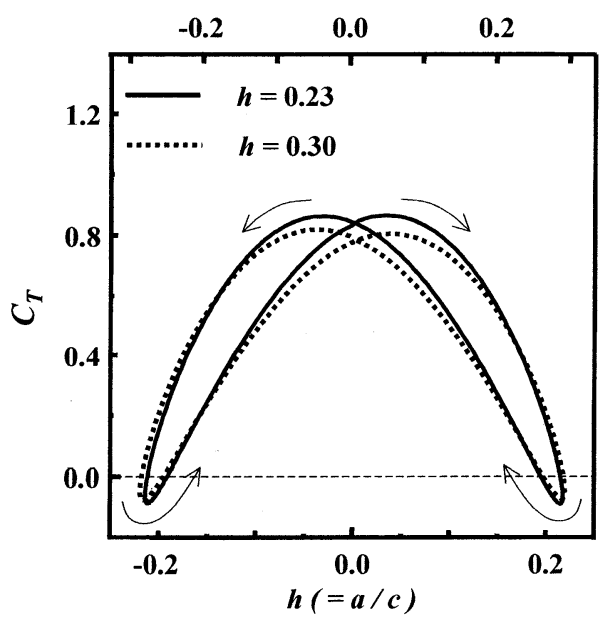

(b) Heaving airfoil at $V_{h}=0.91$

Fig. 9 Hysteresis loops of dynamic thrust at constant $V_{p}$ and $V_{h}$

いる.また, $V_{p}$ が増加するにつれ，非定常推進力の 最大值が大きくなっている.

一方，ヒービング運動翼に働く非定常推進力のヒス テリシスループは凸形となる. 非定常推進力は上死点 $(h=0.3)$ および下死点 $(h=-0.3)$ で最小となり, $h=$ 0.0 付近で最大となる. また， $V_{h}$ が増加するにつれ 非定常推進力の最大值が増加している.しかしなが ら, $V_{h}=1.35$ では, 上死点 $(h=0.3)$ および下死点 $(h$ $=-0.3)$ ではわずかに抗力を発生している. 以上に より，ピッチング運動翼およびヒービング運動翼では 発生する推進力の動的挙動が異なることがわかる.

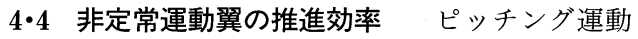
翼に働く非定常モーメント $C_{M}$ およびヒービング運動

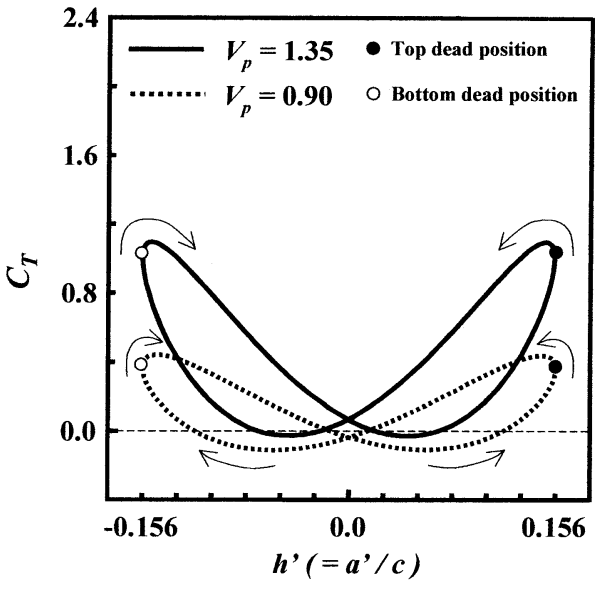

(a) Pitching airfoil at $h^{\prime}= \pm 0.156$

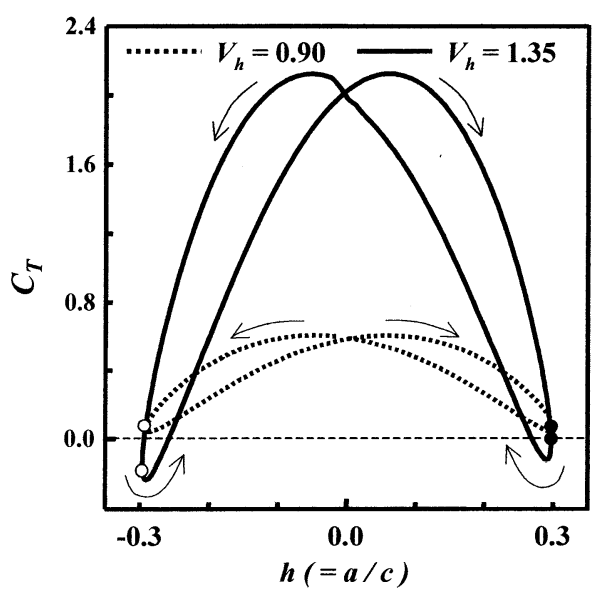

(b) Heaving airfoil at $h= \pm 0.30$

Fig. 10 Hysteresis loops of dynamic thrust at constant $h$ and $h^{\prime}$

翼に働く非定常揚力 $C_{L}$ をそれぞれ図 11（a），(b)に 示す.

ピッチング運動翼およびヒービング運動翼の場合と もに， $V_{p}$ および $V_{h}$ の増加に伴い推進力が増加する ことと同様に, ピッチング運動翼に働く $C_{M}$ およびヒ ービング運動翼に働く $C_{L}$ も急速に増加する.

ピッチング運動翼およびヒービング運動翼の推進効 率クをそれぞれ図 $12(\mathrm{a})$ ，（b ）に示す.ピッチング 運動翼およびヒービング運動翼の推進効率 $\eta$ は, 一般 的にそれぞれ式(1)，（2）で定義されており(13), 本研 究でもこれらを用いた。

$$
\eta_{p}=\frac{1}{T} \int_{0}^{T} \frac{T_{p} V_{0}}{M \omega} d t
$$




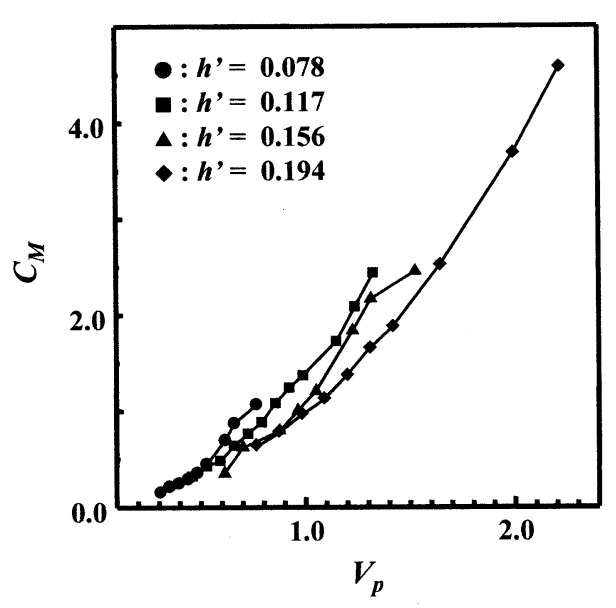

(a) Moment acting on pitching airfoil

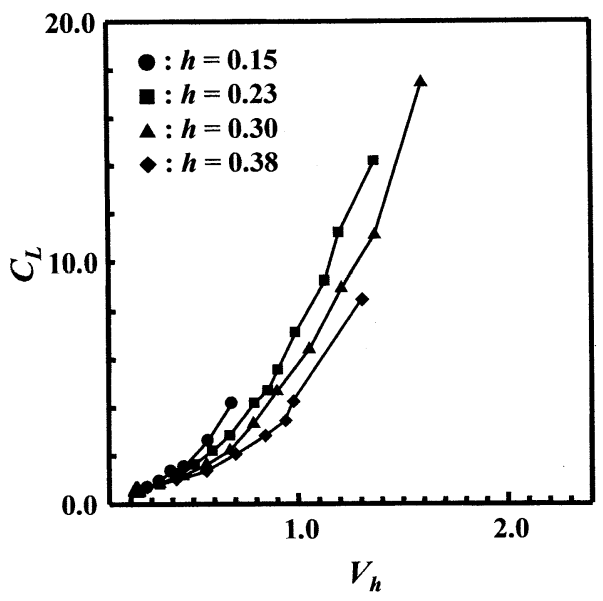

(b) Lift acting on heaving airfoil

Fig. 11 Dynamic moment and lift averaged during one cycle

$$
\eta_{h}=\frac{1}{T} \int_{0}^{T} \frac{T_{h} V_{0}}{L V} d t
$$

ピッチング運動翼の推進効率 $\eta_{p}$ は $V_{p}=0.7$ までは 急速に増加し, その最大值は $\eta_{p}=0.34$ である. $V_{p}>$ 0.7 では, $V_{p}$ の増加につれ, 推進効率は次第に減少し ている.ヒービング運動翼の場合も同様に, 推進効率 $\eta_{h}$ は $V_{h}=0.4$ までは急速に増加し, その後, $V_{h}$ の増 加に従い, 次第に減少している. 図 11 に示すように, $V_{p}$ および $V_{h}$ の増加に伴い, ピッチング運動翼に働 く $C_{M}$ およびヒービング運動翼に働く $C_{L}$ も急速に増 加する. その結果，いずれの翼においても推進効率は， 比較的高い $V_{p}$ および $V_{h}$ では減少する傾向にある. また, 推進効率はヒービング運動翼に比べピッチング 運動翼が高い傾向にある.ヒービング運動翼では揚力

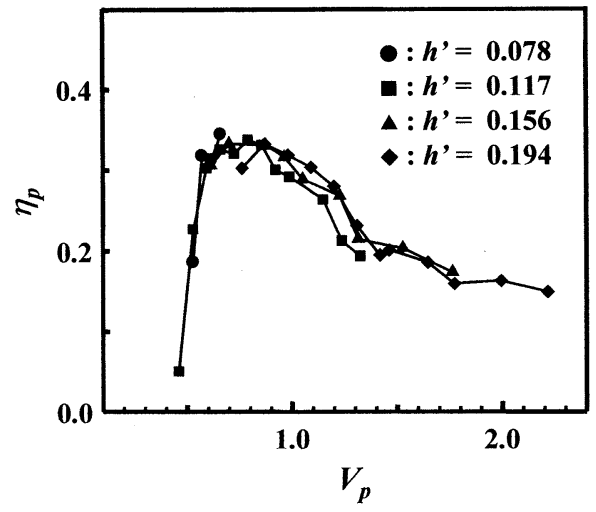

(a) Pitching airfoil

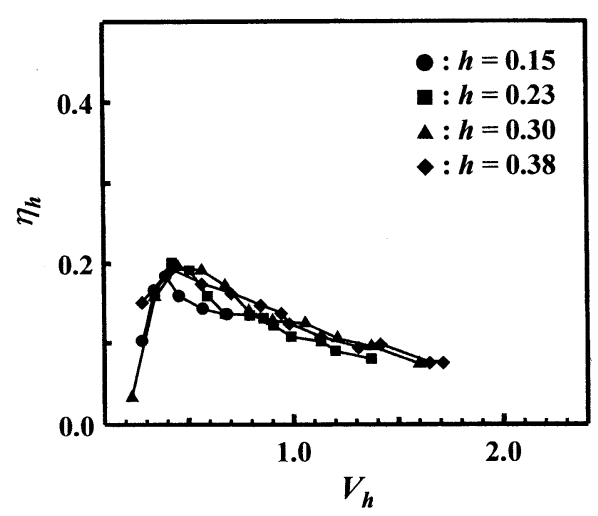

(b) Heaving airfoil

Fig. 12 Thrust efficiency of unsteady airfoils

が非常に大きいために, 推進効率は小さくなってい る.

\section{5. 結 論}

低レイノルズ数領域におけるピッチング運動翼およ びヒービング運動翼の渦流れを PIV 計測により調べ, また，それらに働く非定常推進力特性を非定常流体力 測定実験により調べた.その結果, 以下のことが明ら かになった。

（1）ピッチング運動およびヒービング運動翼後流 には, 翼後縁無次元速度および無次元ヒービング速度 が高くなるにつれ, 推進力発生渦列が明暸に形成され, 推進力発生渦列を形成する渦の渦度が高くなり，それ に誘起される後流の増速部が大きくなる.

（2）ピッチング運動の翼後縁無次元速度およびヒ ービング運動の無次元ヒービング速度が高くなるにつ れ, 非定常推進力の 1 周期あたりの平均値は増加す る.しかしながら, 無次元ピッチング翼後縁振幅およ び無次元ヒービング振幅には依存しない. 
（3）ピッチング運動の無次元ピッチング翼後縁振 幅およびヒービング運動の無次元ヒービング振幅に対 する非定常推進力はそれぞれ凹形および凸形となり， 非定常推進力の動的挙動が異なる. また, 非定常推進 力は無次元ピッチング翼後縁振幅および無次元ヒービ ング振幅の影響は小さく, 翼後縁無次元速度および無 次元ヒービング速度に強く依存する.

（4）ピッチング運動翼の最大推進効率は $V_{p}=$ 0.7 で $\eta_{p}=0.34$ である. 一方, ヒービング運動翼の 最大推進効率は $V_{h}=0.4$ で $\eta_{h}=0.20$ となり, それぞ れの推進効率は無次元ピッチング翼後縁振幅および無 次元ヒービング振幅に依存しない.また，翼後縁無次 元速度および無次元ヒービング速度の全般にわたり, ヒービング運動翼に比ベピッチング運動翼が高い傾向 にある。

本研究は平成 13,14 年度科学研究費補助金 [基盤 研究 (C) (2)] 課題番号 13650187 の援助を受けて行 われたものであることを付記する.

\section{文献}

(1) McCroskey W. J., Trans, ASME, J. Fluid Eng., Vol. 99
(1977), pp. 8-39.

(2) Maresca, C. et al., Trans. ASME, J. Fluid Mech., Vol. 92 (1979), pp. 671-690.

(3) Fuchiwaki, M. and Tanaka, K., JSME International J., $B$, Vol. 43, No. 3 (2000), pp. 443-448.

(4) Fuchiwaki, M. et al., Trans. JSME, Series B, Vol. 65, No. 634, (1999), 1970-1977.

(5) Shin, C. et al., AIAA J., Vol. 30, No. 5 (1992), pp. 11531161.

(6) Rank, M. and Ramaprian, B. R., AIAA J., Vol. 37, No. 3 (1999), pp. 401-403.

( 7 ) Peter F., AIAA J., Vol. 26, No. 7 (1988), pp. 881-883.

(8) Koochesfahani, M. M., AIAA J., Vol. 27, No. 9 (1989), pp. 1200-1205.

(9) Fuchiwaki, M. and Tanaka, K., J. of Visualization, Vol. 4, No. 4 (2001), pp. 323-329.

(10) Jones, K. D. et al., AIAA J., Vol. 36, No. 7 (1998), pp. 1240-1246.

(11) Joseph, C. L. and Platzer, M. F., ASME, Fluid Eng. Division Summer Meeting, FEDSM 98-4946 (1998).

(12) Lai, J. C. S. and Platzer M. F., AIAA J., Vol. 37, No. 12 (1999), pp. 1529-1537.

(13) Jones, K. D. et al., AIAA 39th Aerospace Sciences Meeting and Exhibit AIAA-2001-0126 (2001).

(14) Yang, C. J. et al., Trans. JSME, Series B, Vol. 71, No. 634 (2005), pp. 104-110.

(15) Ramamurti, R. and Sandberg, W., AIAA J, Vol. 39, No. 2 (2001), pp. 253-260. 